\title{
Mediastinal paraganglioma successfully resected by robot-assisted thoracoscopic surgery with en bloc chest wall resection: a case report
}

\author{
Hiroaki Shidei ${ }^{1 \dagger}$, Hideyuki Maeda $^{1^{*} \dagger}$, Tamami Isaka ${ }^{1}$, Takako Matsumoto ${ }^{1}$, Tomoko Yamamoto ${ }^{2}$, \\ Yoji Nagashima ${ }^{2}$ and Masato Kanzaki ${ }^{1}$
}

\begin{abstract}
Background: Robot-assisted thoracoscopic surgery (RATS) is useful for surgery in the apical region of the chest cavity, as it narrows towards the head. Here, we describe a nonfunctional, rib-invasive paraganglioma arising in the posterior mediastinum that was successfully removed using RATS combined with chest wall resection.

Case presentation: A 31-year-old woman presented with a posterior mediastinal mass on chest computed tomography (CT) scan during a medical check-up 2 years prior. Positron emission tomography/computed tomography scan with F-18 fluorodeoxyglucose revealed a mass associated with standardized uptake maximum value of 2.69. With a preoperative diagnosis of neurogenic tumor by CT-guided percutaneous fine-needle aspiration biopsy, we performed robot-assisted tumor resection combined with chest wall resection. The wristed instruments of the robotic surgical system have increased range of motion and enabled the tumor resection without organ injury in the thoracic cavity. Histopathology examination revealed a non-functional paraganglioma with rib invasion.

Conclusions: RATS is a useful technique, enabling safer and easier resection of a mediastinal tumor adjacent to surrounding organs.
\end{abstract}

Keywords: Mediastinal tumor, Robot-assisted thoracoscopic surgery, Paraganglioma

\section{Background}

Mediastinal paragangliomas are rare tumors that arise from extra-adrenal paraganglionic cells of the sympathetic nerve system; they are commonly known as pheochromocytomas. Paragangliomas are classified as functional or nonfunctional based on their ability to synthesize and release catecholamines.

Robot-assisted thoracoscopic surgery (RATS) has been used to overcome the limitations of video-assisted thoracoscopic surgery with favorable results for mediastinal tumors; the number of RATS procedures has increased rapidly in Japan $[1,2]$. Here, we report the case of a nonfunctional, rib-invasive paraganglioma arising in the

\footnotetext{
* Correspondence: maeda.hideyuki@twmu.ac.jp

${ }^{+}$Hiroaki Shidei and Hideyuki Maeda contributed equally to this work.

${ }^{1}$ Department of Thoracic Surgery, Tokyo Women's Medical University, 8-1

Kawada-cho, Shinjuku-ku, Tokyo 162-8666, Japan

Full list of author information is available at the end of the article
}

posterior mediastinum that we removed using RATS combined with chest wall resection. To the best of our knowledge, this is the first reported use of RATS for a posterior mediastinal tumor combined with chest wall resection.

\section{Case presentation}

A 31-year-old woman presented with a posterior mediastinal mass on chest computed tomography (CT) scan during a medical check-up two years prior. She had left shoulder pain presentation to our hospital. Contrastenhanced CT revealed a solitary and non-homogeneous 4- $\mathrm{cm}$ mass in the posterior mediastinum invading the left 2nd rib (Fig. 1a, b, c). Magnetic resonance imaging (MRI) revealed that signal inside the mass was equivalent to muscle tissue on the T1-weighted image, and was hyperintense on the T2-weighted image (Fig. 1d, e).

(c) The Author(s). 2020 Open Access This article is distributed under the terms of the Creative Commons Attribution 4.0 International License (http://creativecommons.org/licenses/by/4.0/), which permits unrestricted use, distribution, and 

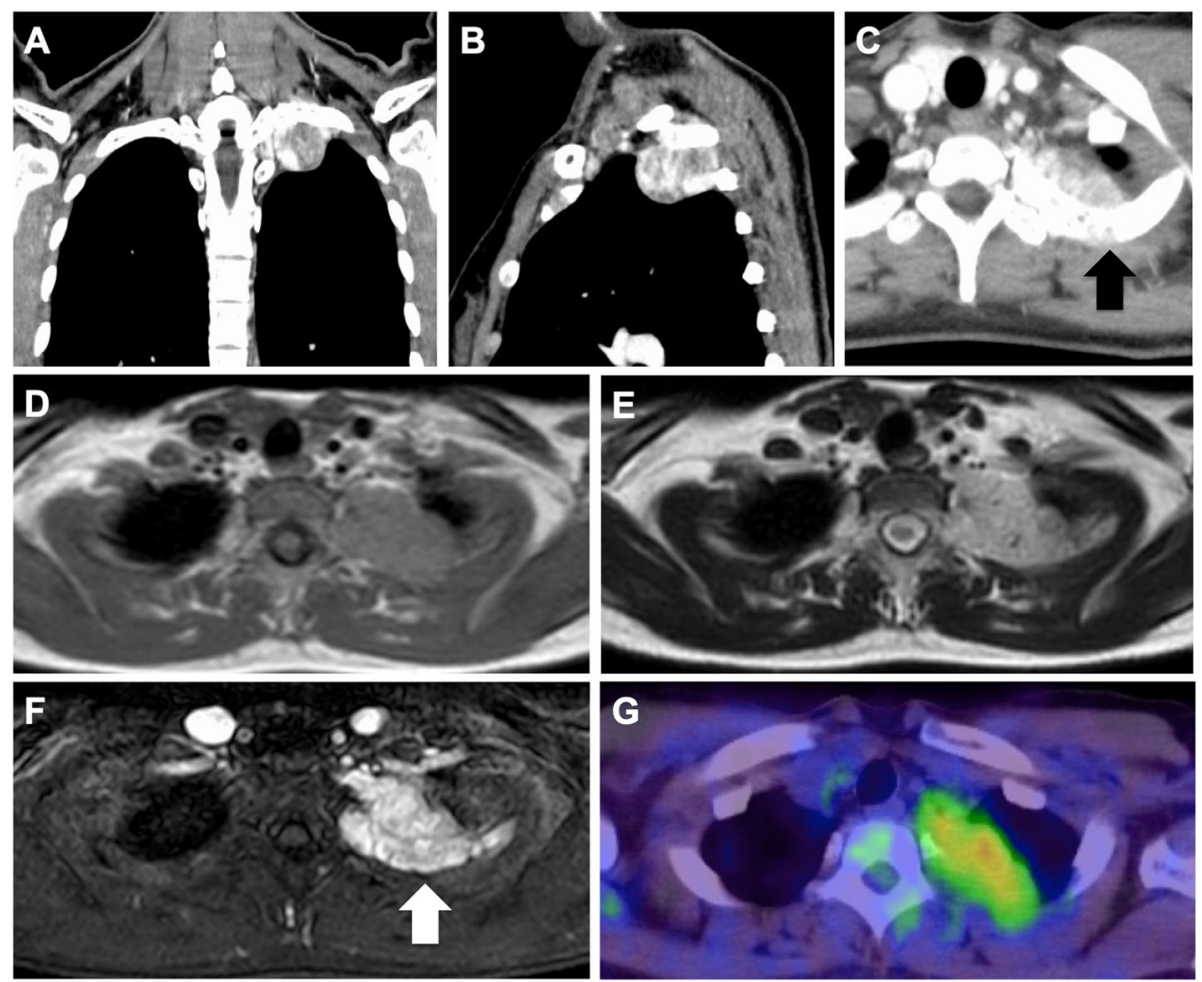

Fig. 1 a Contrast-enhanced computed tomography revealing a solitary nonhomogeneous 4-cm mass in the posterior mediastinum. b, c The mass invaded the left 2nd rib (black arrow). $\mathbf{d}$, e Magnetic resonance imaging (MRI) showing that the signal inside the mass was representative of muscle tissues equivalent to that on the T1-weighted image and hyperintense on the T2-weighted image. $\mathbf{f}$ Contrast-enhanced MRI showing similar signal changes and contrast effects on the dorsal side of the second rib in contact with the tumor. Bone infiltration is noted (white arrow). g Positron emission tomography/computed tomography scan with F-18 fluorodeoxyglucose showing standardized uptake values of 2.69

Contrast-enhanced MRI showed similar signal changes and contrast effects on the second rib dorsal side in contact with the tumor. Bone infiltration was noted (Fig. 1f). Positron emission tomography/computed tomography scan with F-18 fluorodeoxyglucose suggested that the mass was associated with increased standardized uptake $(\max =2.69)$ (Fig. 1g). All laboratory data were within normal ranges. CT-guided percutaneous fine-needle aspiration biopsy was performed, and she was diagnosed with a neurogenic tumor. We planned tumor resection by RATS combined with chest wall resection.

Under general anesthesia, the robot was positioned at the head of the operating table. The patient was intubated with a nerve integrity monitor electromyogram endotracheal tube for intraoperative neuromonitoring and place.

Robotic 8-mm ports were introduced (Fig. 2a). The da Vinci $\mathrm{Xi}^{\odot}$ system (Intuitive Surgical, Sunnyvale, CA, USA) was then docked to the patient, and we explore the left pleural cavity (Fig. 2b). The tumor originated from the posterior mediastinum between the first and fourth rib, invading the posterior chest wall with no invasion of the vessels. The parietal pleura surrounding the tumor was resected with the robotic electrocautery, and both the second and third ribs were exposed proximally and distally. The edge was dissected from the lower edge of the first rib to the upper edge of the fourth rib. As the preoperative CT findings showed, the tumor invaded the second rib. The first and second intercostal muscles were dissected to secure the surgical margin. After that the second rib was cut down through the posterior incision, and the tumor was removed in its entirety, including the chest wall, from the thoracic cavity. After confirming hemostasis, the robot was undocked. A 21-F chest tube was inserted to the thoracic cavity through the camera port at the eighth intercostal space, and the wounds were closed. The postoperative course was uncomplicated. She has had no recurrences of the tumor after surgery.

Grossly, the resected tumor was a tan red-colored, irregular-surfaced and ovoid-shaped mass measuring $4.5 \times 3.3 \times 2.2 \mathrm{~cm}$ (Fig. 3a). Histologically, the tumor cells formed nests surrounded by a fine vascular network. The tumor cells ranged spindle to polygonal in shape. Their nuclei were spindle shape, and contained fine chromatin and inconspicuous nucleoli. The cytoplasm was abundant and eosinophilic. Marked atypism was absent (Fig. 3b). The tumor invaded the bony tissue 

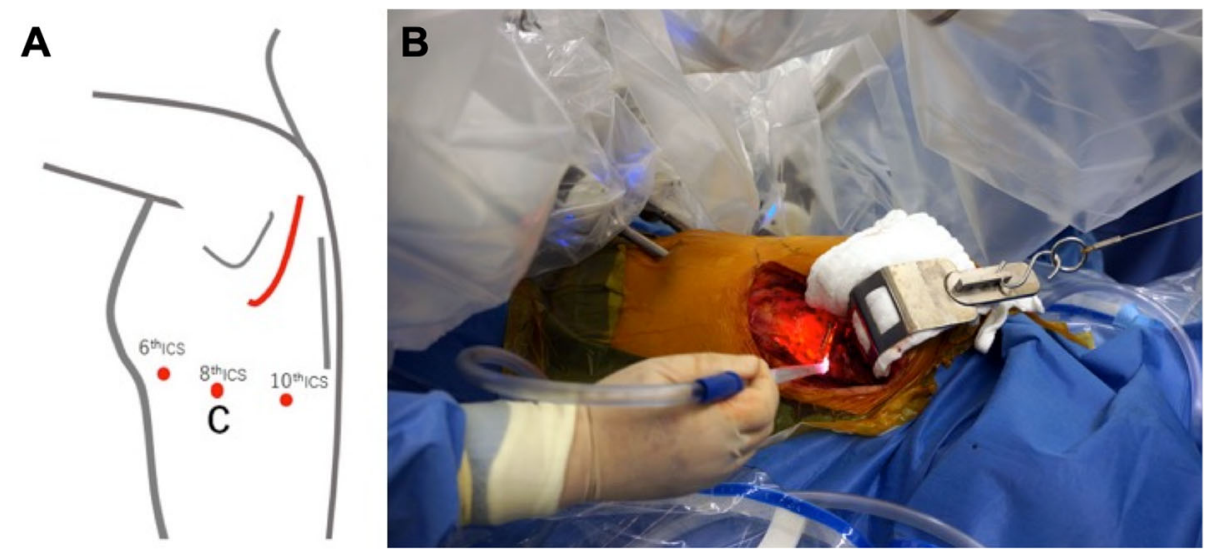

Fig. 2 a Port placement (red circle) and posterior skin incision (red line). (ICS, Intercostal; C, Camera). b Intraoperative findings after the da Vinci surgical system was docked with the patient, and the left chest was explored

of the rib included in the specimen (Fig. 3c). Immunohistochemically, the tumor cells were positive for chromogranin, and synaptophysin. Anti-S100 protein immunostain highlighted the sustentacular cells in the tumor, (Fig. 3d, e, f). Based on these findings, the tumor was diagnosed as paraganglioma with invasion to the rib. Because urinary adrenaline and metanephrine were within normal ranges, the tumor was considered to be nonfunctional. According to the grading system for adrenal pheochromocytoma and paraganglioma (GAPP) score [3], histological pattern was zellballen ( 0 point), cellularity was low $(<150$ cells/HPF $) \quad(0$ point $)$, Kilabeling index was $1-3 \%$ (1 point), and the tumor invaded the rib ( 2 point) and had non-functional $(0$ point). The total score was 3 . An additional resection was not performed.

\section{Discussion and conclusions}

Various approaches have been described for surgical treatment of neurogenic mediastinal tumors. These include thoracotomy $[4,5]$, neck approaches, transmanubrial approaches [6-8], thoracoscopic surgery [9, 10], and combinations of these procedures [11]. The da Vinci ${ }^{\odot}$ robotic surgical system (Intuitive Surgical, Sunnyvale, CA, USA) enables highly accurate, minimally invasive procedures. In particular, the $3 \mathrm{D}$ imaging and multi-jointed forceps of the da Vinci ${ }^{\circ}$ system allows procedures deep in the thoracic cavity to be performed much more easily than in conventional thoracoscopic surgery [1]. These advantages also enable reconstruction of vessels under thoracoscopic view. Suda et al. reported robot-assisted thymectomy with vascular replacement, they described that the robotic arms with movable joints
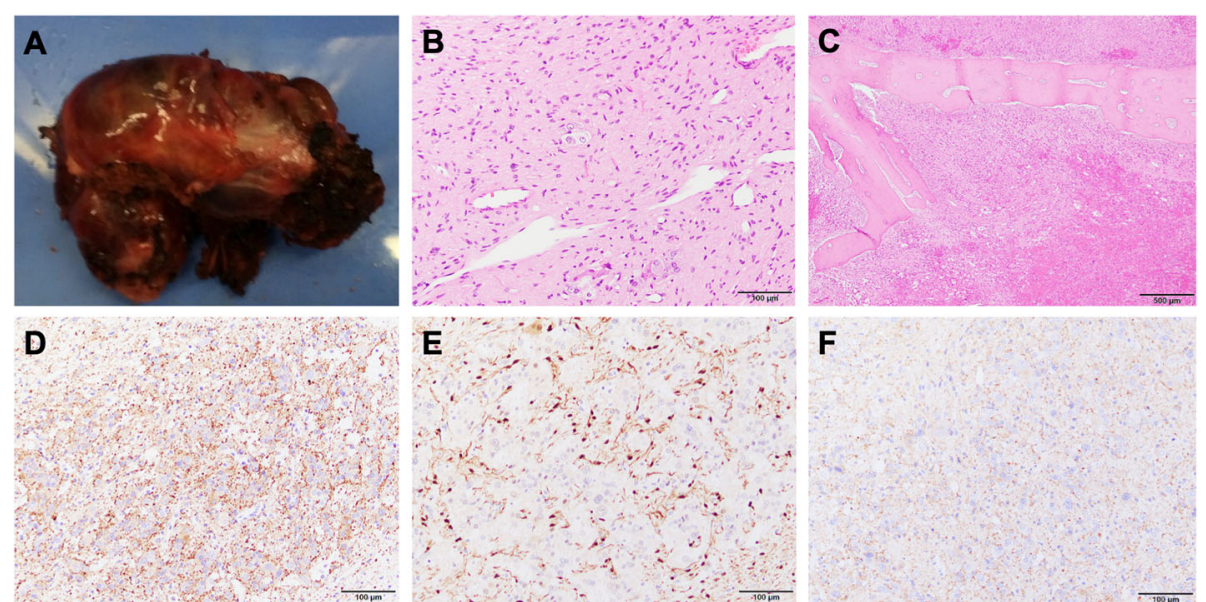

$\mathbf{F}$

Fig. 3 a Macroscopic findings of the resected specimen. The tumor consists of a tan red irregular ovoid mass measuring $4.5 \times 3.3 \times 2.2 \mathrm{~cm}$. $\mathbf{b}$ The specimen is stained with hematoxylin-eosin; original magnification: $\times 20$. The specimen is a nodular lesion continuous with the peripheral nerve, characterized by epithelial-like cells with abundant proliferating eosinophilic endoplasmic reticulum forming small clusters. There are a few atypical spindle cells in the background. $\mathbf{c}$ Rib bone tissue stained with HE revealing invasion; original magnification: $\times 4$. The specimen is also stained with $\mathbf{d}$ S-100, e chromogranin and $\mathbf{f}$ synaptophysin; original magnification: $\times 20$ 
similar to those of humans without physiological tremor facilitates vascular prosthetic replacement through endto-end anastomosis [12].

In the present case, we performed tumor resection using RATS combined with chest wall resection. Although the mediastinum is tightly packed with intertwined organs and conduits, the wristed instruments of the robotic surgical system have increased range of motion and enabled the tumor resection without organ injury in the thoracic cavity. In addition, some authors reported the postoperative course of RATS. In comparison with conventional median sternotomy and VATS approach, RATS revealed lower amount of postoperative drainage, shorter duration of chest drainage and length postoperative hospital stay [13]. These results reflect less invasiveness of RATS.

Paragangliomas develop from chromaffin cells of the sympathetic nervous system distributing over the body [14]. Most mediastinal paragangliomas originate in the posterior portion [15]. Diagnosis of a functional paraganglioma requires urinary adrenaline or metanephrine levels three times higher than normal reference values. In this case, these values were within normal range. There is no established treatment other than surgical resection for paraganglioma $[16,17]$. The prognosis is favorable in cases of complete resection, but the outcomes might be poor in malignant cases with residual tumor [18]. Even if tumor is histologically benign, it may clinically manifest a malignant behavior. Subsequently, longterm follow-up is mandatory for paraganglioma [19]. Although the tumor invaded the rib and the GAPP score in this case indicated histological grade was moderately differentiated type [3], successful resection was performed in our patient, and a favorable prognosis was expected.

In conclusion, RATS is a useful procedure, enabling safe and minimally invasive resection of mediastinal tumors invading the surrounding organs. Further applications in thoracic surgery are expected in the future.

\section{Abbreviations}

CT: Computed tomography; GAPP: Grading system for adrenal pheochromocytoma and paraganglioma; RATS: Robot-assisted thoracoscopic surgery

\section{Acknowledgements}

Not applicable.

\section{Authors' contributions}

$\mathrm{SH}, \mathrm{MH}, \mathrm{IT}, \mathrm{MT}$ and $\mathrm{KM}$ were involved in the design and drafting of the study. YT and NY provided the pathological findings. The author(s) read and approved the final manuscript.

\section{Funding}

There is no funding source for this case report.

Availability of data and materials

Not applicable.
Ethics approval and consent to participate

Not applicable.

\section{Consent for publication}

Written informed consent was obtained from the patient. This consent is for all potentially identifiable clinical data and accompanying images, and this is available for review by the editor of BMC surgery.

\section{Competing interests}

The authors declare that they have no competing interests.

\section{Author details}

${ }^{1}$ Department of Thoracic Surgery, Tokyo Women's Medical University, 8-1 Kawada-cho, Shinjuku-ku, Tokyo 162-8666, Japan. ${ }^{2}$ Department of Surgical Pathology, Tokyo Women's Medical University, 8-1 Kawada-cho, Shinjuku-ku, Tokyo 162-8666, Japan.

Received: 18 September 2019 Accepted: 17 February 2020

Published online: 05 March 2020

\section{References}

1. Kanzaki M Current status of robot-assisted thoracoscopic surgery for lung cancer. Surg Today. 2019. doi: https://doi.org/10.1007/s00595-019-01793-x Pubmed:30859310.

2. Homma T, Kitamura N, Ojima T, Akemoto Y, Hida Y, Yoshimura N. Initial experiences of robot-assisted thoracic surgery: safety approach and comparison with video-assisted thoracoscopic surgery. Jpn J Chest Surg. 2019;33(2):113-21. https://doi.org/10.2995/jacsurg.33.113.

3. Kimura N, Takayanagi R, Takizawa N, et al. Pathological grading for predicting metastasis in phaeochromocytoma and paraganglioma. Endocr Relat Cancer. 2014;21(3):405-14. https://doi.org/10.1530/ERC-13-0494.

4. Gyhra A, Israel J, Santander C, Acuña D. Schwannoma of the brachial plexus with intrathoracic extension. Thorax. 1980;35(9):703-704 doi: https://doi.org/ 10.1136/thx.35.9.703 Pubmed:7444844.

5. Takaji K, Yoshioka M, Mori T, Tsuruzoe S, Tabira Y, Tanaka M, et al. A case of schwannomaarising in brachial plexus with intrathoracic extension. Jpn J Chest Surg. 1999:13(5):700-4. https://doi.org/10.2995/jacsurg.13.700.

6. Suzuki H, Kou E, Hoshino H, Saitoh Y, Fujisawa T. An operative case of schwannoma arising in the brachial plexus (C8, T1). Jpn J Chest Surg. 2008; 22(2):175-9. https://doi.org/10.2995/jacsurg.22.175.

7. Akiba T, Ishiyama M, Marushima H, Nojima K, Kobayashi S, Morikawa T. Temporary claviculectomy approach for plexiform neurofibroma of the first intercostal nerve. Surg Today. 2009;39(6):544-547 doi: https://doi.org/10. 1007/s00595-008-3905-5 Pubmed:19468815.

8. Mitsuboshi S, Isaka T, Maeda H, Kikkawa T, Nagashima Y, Kanzaki M. Superior mediastinal paraganglioma resected using a modified transmanubri alapproach: a case report. Jpn J Chest Surg. 2017;31(7):957-62. https://doi. org/10.2995/jacsurg.31.957.

9. Pons F, Lang-Lazdunski L, Bonnet PM, Meyrat L, Jancovici R. Videothoracoscopic resection of neurogenic tumors of the superior sulcus using the harmonic scalpel. Ann Thorac Surg. 2003;75(2):602-604 doi: https://doi.org/10.1016/s0003-4975(02)04160-7 Pubmed:12607692.

10. Arapis C, Gossot D, Debrosse D, Arper L, Mazel C, Grunenwald D. Thoracoscopic removal of neurogenic mediastinal tumors: technical aspects. Surg Endosc. 2004;18(9):1380-1383 doi: https://doi.org/10.1007/s00464-0039329-9 Pubmed:15803239.

11. Yamaguchi M, Yoshino I, Kameyama T, Osoegawa A, Tagawa T, Maehara Y. Thoracoscopic surgery combined with a supraclavicular approach for removing a cervico-mediastinal neurogenic tumor: a case report. Ann Thorac Cardiovasc Surg. 2006;12(3):194-196 Pubmed:16823333.

12. Suda T, Nagano H, Kawai H, Hoshikawa Y. Subxiphoid Robot-Assisted Thymectomy With Vascular Prosthetic Replacement. Semin Thorac Cardiovasc Surg. 2019. pii: S1043-0679(19)30164-9. doi: https://doi.org/10. 1053/j.semtcvs.2019.06.007.

13. Qian L, Chen X, Huang J, Lin H, Mao F, Zhao X, Luo Q, Ding Z. A comparison of three approaches for the treatment of early stage thymomas: robot-assisted thoracic surgery, video-assisted thoracic surgery, and median sternotomy. J Thorac Dis. 2017;9(7):1997-2005. https://doi.org/ 10.21037/jtd.2017.06.09.

14. Spector JA, Willis DN, Ginsburg HB. Paraganglioma (pheochromocytoma) of the posterior mediastinum: a case report and review of the literature. J 
Pediatr Surg. 2003;38(7):1114-1116 doi: https://doi.org/10.1016/s00223468(03)00208-2 Pubmed:12861555.

15. Sakamaki Y, Yasukawa M, Kido T. Pheochromocytoma of the posterior mediastinum undiagnosed until the onset of intraoperative hypertension. Gen Thorac Cardiovasc Surg. 2008;56(10):509-511 doi: https://doi.org/10. 1007/s11748-008-0282-3 Pubmed:18854928.

16. Olson JL, Salyer WR. Mediastinal paragangliomas (aortic body tumor): A report of four cases and a review of the literature. Cancer. 1978:41(6):24052412 doi: https://doi.org/10.1002/1097-0142(197806)41:6<2405::aidcncr2820410646>3.0.co;2-e Pubmed:207409.

17. Moran CA, Suster S, Fishback N, Koss MN. Mediastinal paragangliomas. A clinicopathologic and immunohistochemical study of 16 cases. Cancer. 1993;72(8):2358-2364 doi: https:/doi.org/10.1002/1097-0142(19931015)72:8< 2358:aid-cncr2820720811>3.0.co;2-b Pubmed:8402449.

18. Sclafani LM, Woodruff JM, Brennan MF. Extraadrenal retroperitoneal paragangliomas: natural history and response to treatment. Surgery. 1990; 108(6):1124-1129; discussion 1129 Pubmed:2174194.

19. Adachi T, Sakuraba M, Murasugi M, Miyano H, Kuwata H, Ikeda T, et al. A case of primary mediastinal paraganglioma who received combination treatments. Jpn J Chest Surg. 2002;16(7):779-83. https://doi.org/10.2995/ jacsurg.16.7_779

\section{Publisher's Note}

Springer Nature remains neutral with regard to jurisdictional claims in published maps and institutional affiliations.

Ready to submit your research? Choose BMC and benefit from:

- fast, convenient online submission

- thorough peer review by experienced researchers in your field

- rapid publication on acceptance

- support for research data, including large and complex data types

- gold Open Access which fosters wider collaboration and increased citations

- maximum visibility for your research: over $100 \mathrm{M}$ website views per year

At BMC, research is always in progress.

Learn more biomedcentral.com/submissions 